\title{
Tufts Polymer Laboratory Silently Buzzes with Enthusiasm Peggy Cebe
}

As a scientist and academic at Tufts University who spends most of her time in laboratories and classrooms, I have often wondered how to use my expertise to directly help underserved populations. Although other volunteer opportunities abound, providing research opportunities in my laboratory for such a group has become my way to make a difference in the lives of young students. And I cannot recommend it highly enough. While doing a good job takes a lot of time, the benefits of service far outweigh the costs. The joy and satisfaction of helping others is the best and most lasting reward. I am changed for the better. But my experience is really about 26 young men and women who, over the past seven years, have spent their summers in my research laboratory focused on polymer materials science. The story belongs to them.

The interns are in high spirits, having just successfully completed the practical exam that will qualify them for use of the Fourier transform infrared spectrometer. Each intern is tested individually and, one by one, each is welcomed back to the group with "high fives," as they commiserate with their friends on some of the tougher questions. In our meeting immediately afterward I attempt to discuss how to improve the materials properties of their solution-cast polymer films. But the interns are still quite excited, and continue to joke back and forth.

For my research group this is quite normal. But most observers would find this meeting to be completely atypicalbecause not a word has been spoken. The room is buzzing yet it is quiet because all four interns are deaf or hard of hearing $(\mathrm{DHH})$, and to accommodate their various communication skills, this meeting is conducted using laptop computers and a live chat room, made possible by a wireless Internet connection to the Tufts Blackboard academic Web site (http: / /blackboard.tufts.edu).

It was not always as seamless. Frankly, I was quite nervous the day my first intern arrived (for a pilot project in 2003). I had never worked with a DHH student in my laboratory before. In anticipation, I had carefully practiced finger spelling "Hello, I am Prof. Cebe," and when she peeked around the door of my office and waved to me, I panicked and ran to get the American Sign Language interpreter. But little by little, my comfort zone expanded. I realized that $\mathrm{DHH}$ interns need just what hearing students need: clear instructions, close supervision until competency is developed, help with synthesizing brand new concepts, and the

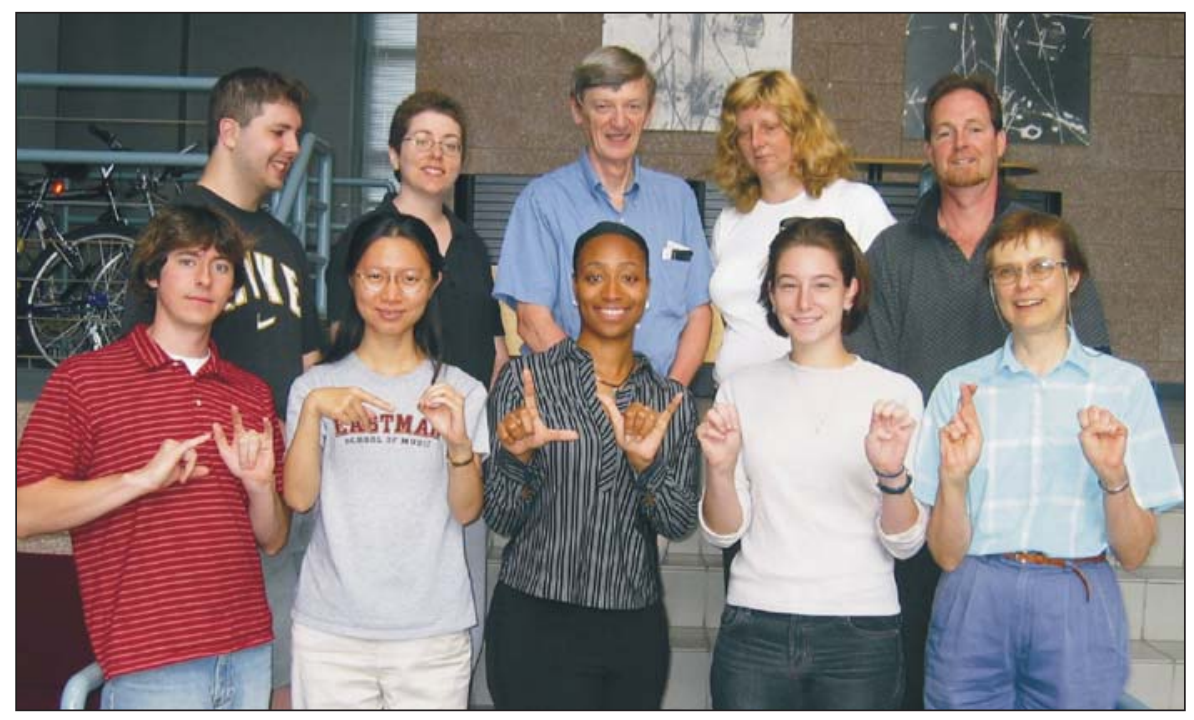

Summer School at Tufts. The first row signs "I-love-P-O-L-Y-M-E-R-S." (Front row, left to right): Matthew Jenkins (RIT), Jingjing Pan (RIT), Niesha Washington (Gallaudet), Jennifer Buckley (RIT), and Prof. Peggy Cebe (Tufts); (back row, left to right): Daniel Cherdack (teaching assistant, Tufts), Diane McKoen (ASL interpreter), Instructors Prof. Terry Hass and Dr. Regina Valluzzi (Tufts), and Mark Riley (ASL Interpreter).

realization that I have very high expectations of them. The only difference is that communication with $\mathrm{DHH}$ interns is more varied, and often non-oral.

The range of communications skills of the DHH students is not known until they actually arrive at my laboratory. They might sign, voice, lip-read, write-and many use a combination. Some are very oral; others not at all. Over the years, I have made adjustments in my laboratory to accommodate the needs of individual interns to enable them to conduct research in a "hearing" environment. For example, since $\mathrm{DHH}$ students take in information visually, we now provide the interns with standard operating procedures manuals for all instruments. We use both high-tech and low-tech solutions for communication: typing on a computer, instant messaging, writing on paper, using hand motions to demonstrate techniques, finger spelling (albeit slowly!). Because of advances in technology, we use LCD screens and projectors to both communicate through typing and to present information. And of course, the students are quite adept at live chatting because this

INTERFACES seeks articles featuring the people and profession of materials. Send proposals to Bulletin@mrs.org. method is actually how they communicate to each other outside of class these days.

In 1993 when I first began to notice my progressive hearing loss, I became sensitized to the challenges faced by $\mathrm{DHH}$ students. But the true genesis of the internship program began with my sabbatical in 2002 when I decided to write a popular lecture that was based in science but intended for a more general audience. After some discussion with and encouragement from my sister, who had received her graduate degree from Gallaudet University, the premier liberal arts institution for the deaf, I offered to present the lecture there. It was my first exposure to the DHH students and I was so impressed by their enthusiasm and interest that I started talking to Gallaudet's faculty about the potential of a program geared toward DHH science majors that would provide an intensive laboratory experience. The idea took hold.

Funded by the National Science Foundation since 2003, this unique, summer internship provides an opportunity for four or five $\mathrm{DHH}$ interns to participate in a six-week, highly integrated classroom and laboratory program, based upon investigations of polymeric materials. While the materials research topic varies, from Polymeric Smart Materials (2003-2008) to Polymers for Fuel Cell Technologies (2009-2011), the internship experience is similar from year to year. All the students 
are science majors and come largely from either Gallaudet or the National Technical Institute for the Deaf, which is part of Rochester Institute of Technology (RIT). Because the interns are students in the Summer School at Tufts, they earn course credit and live together in Tufts dormitory housing.

For six hours a week, the interns are in the classroom, during which time professional American Sign Language interpreters are provided. The classroom lessons provide the materials science and engineering underpinnings for the laboratory work and are taught by four Tufts faculty from the Departments of Chemistry and Physics, all of whom are donating their time.

The rest of the work week, about 32 hours, is spent in my research laboratories, making and testing polymer films. The first few days of each session are rough but we keep the standards high. Some are terrified of large equipment the likes of which they have never seen before. Unlike a typical laboratory course (students performing a laboratory task with predictable outcome), this internship exposes the students to the possibility of failure.

At the outset I was worried that if the interns were to work on a project alone, they would become too isolated and I would not be able to provide the intense personal attention that I felt was needed. To overcome this concern,

I decided that they would work together as a team and complete one project under my direction. The interns do not focus on a tiny piece of another research program, nor on a "toy" project. I have watched the students become involved with their materials as they collect and analyze real data to address a significant scientific question. The interns bear full responsibility for their project's success and at the end of the session present their results. Nearly every group has either published their work in peer-reviewed journals, or has publications pending.

This strategy had the desired effect: The students bond with their peers, learn to contribute appropriately to the team effort, and feel part of a unified endeavor; they learn cooperation and teamwork, leadership, and compromise. Moreover, the team approach mitigates the potential feelings of isolation that can be especially problematic-and to which attention must be paid-with any minority population. The cultural and social dynamics of a research group are very important, as any research supervisor knows. For these students, their cultural identity as deaf or hard of hearing and their association with a "team" are significant factors in building group camaraderie.

The high research standards have paid off...as evidenced by the students' comments. "I went into this internship thinking that I have experienced research before," one student reflected, "so I thought that I wouldn't be learning too much in that aspect, but this opportunity was an eye opener....After the experience I had at Tufts University I feel much more confident in how to perform high end research anywhere I might decide to go after graduation....This was a career changing experience for me." Another tells us, "...the hands-on experience and education have built my confidence, enthusiasm and professionalism for polymer science...."

Perhaps most significant is the effect that the program seems to have on the dreams and aspirations of the students. "The experiences... taught me so much about laboratory procedures," wrote one young man, "that it helped me secure future jobs at Bristol-Myers-Squibb and Pratt \& Whitney." This former intern is now a graduate student in Materials Science and Engineering at the State University of New YorkStony Brook.

"My experience at Tufts University was priceless," reflected a young woman. "I am very dedicated to my goals but with my hearing impairment it is not always easy....What the NSF experience taught me the most is that I can reach my goals."

Writes another intern, "My goal is to obtain an M.D./ Ph.D....I can be a role model for other deaf peers who are interested in pursuing a career in the sciences. My experience at Tufts has been a major stepping stone to achieving my goals."

And perhaps most telling of all: "...the fact we were deaf was hardly an issue." Which was probably the point all along.

Peggy Cebe is professor of physics in the School of Arts and Sciences at Tufts University, and can be contacted at peggy.cebe@ tufts.edu. For more information about the internship see the group's YouTube video at www youtube.com/watch? $v=C x A y$ GIlkN9U and Web site at wwww. tufts.edu/ pcebe/. 